Dickinson, David L. (2005). Bargaining Outcomes with Double-Offer Arbitration. Experimental Economics, 8(2): 145-66. (June 2005)

Published by Springer Verlag. (ISSN: 1573-6938) The original publication is available at www.springerlink.com.

\title{
Bargaining Outcomes with Double-Offer Arbitration
}

\section{David L. Dickinson}

Dept. of Economics

Appalachian State University

Boone, North Carolina, 28608

Phone: 828-262-7652

Fax: 828-262-6105

E-mail: dickinsondl@appstate.edu

\begin{abstract}
Increasingly, arbitration is becoming used to resolve bargaining disputes in a variety of settings. Reducing dispute rates is often listed as a main goal in designing arbitration mechanisms. Conventional arbitration and final-offer arbitration are two commonly used procedures, but theoretical examinations of these arbitration procedures show that disputants' final bargaining positions do not converge and disagreement is likely. This article contains results from a set of experiments designed to compare bargaining outcomes under the two commonly used arbitration procedures with outcomes under an innovative procedure called “double-offer” arbitration (Zeng et al. 1996). This procedure requires that disputants make two final offers at impasse: a primary and a secondary offer. The arbitrator evaluates the pairs of offers using a linear criterion function, and theory suggests the secondary offers converge to the median of the arbitrator's preferred settlement distribution. Because the procedure's rules are that convergence of offers generates a settlement at those offers, this theoretical convergence result implies that arbitration is not needed in the end. Experimental results indicate that dispute rates in double-offer arbitration are, on average, about the same as dispute rates in conventional arbitration. However, other results show reason to favor double-offer arbitration. Specifically, in repeated bargaining, there is concern over whether use of an arbitration procedure becomes addictive and makes bargainers more likely to use the procedure in the future- $-\mathrm{a}$ "narcotic effect." The data show that double-offer arbitration is non-addictive, whereas both conventional and final-offer arbitration are.
\end{abstract}

JEL Keywords: Dispute/Conflict Resolution, Experiments, Expectations

JEL Codes: J52, D74, D84, C90 


\section{Introduction}

Arbitration is becoming increasingly used to resolve disputes and selectively replace trials for the litigation of certain civil disputes. Its promulgation is due in large part to the savings on money and time costs it promises compared to litigation. Arbitration is used to settle disputes in a variety of settings, though it is perhaps most apparent in resolving labormanagement disputes. One could define a dispute as the lack of agreement in negotiations at a particular point in time (i.e., impasse), and the use of an arbitrator can at least guarantee an outcome. The Supreme Court recently ruled that employers can require individuals to agree to arbitrate employment disputes even as a condition of employment, and so this increasing use of arbitration is likely to continue. ${ }^{1}$

Existing research has examined the theoretical incentives of the types of arbitration rules used in practice (Crawford, 1979; Farber and Katz, 1979; Farber, 1980; Brams and Merrill, 1983). When disputants are uncertain about what settlement the arbitrator would prefer, then the zero-sum game incentives typically generate Nash equilibrium final bargaining positions that do not converge. Convergence of final offers refers to when they are equal or have criss-crossed (that is, the buyer's final offer is greater than or equal to the seller's final offer), which implies that arbitration is no longer needed because the buyer's willingness to pay is now at least as great as the seller's willingness to accept. The two most commonly practiced arbitration procedures are conventional arbitration and final-offer arbitration. In conventional arbitration the arbitrator makes an unconstrained choice of an arbitrated settlement, whereas in final-offer arbitration the disputants each make a final offer and the arbitrator is constrained to choose one of these as the binding settlement. Final-offer arbitration was suggested by Stevens (1966) as a way of conducting arbitration that might make voluntary settlement more likely, but theoretical and 
empirical research has shown that this is not necessarily the case (see Farber, 1980; Brams and Merrill, 1983; Ashenfelter et al., 1992; Dickinson, 2004). Since voluntarily negotiated settlements are generally considered superior to mandated settlements (see Crawford, 1979), any measure that can be introduced to promote more good faith negotiations and less reliance on third-party settlements can significantly improve dispute resolution both from an efficiency, as well as a cost, standpoint.

The focus of this article is an innovative procedure developed in Zeng et al. (1996), called double-offer arbitration. The rules of this procedure are such that disputants' final offers are predicted to converge, thereby eliminating the actual use of the procedure. This innovative procedure requires disputants to submit both a primary and a secondary final offer at impassethese are the "double” offers. The primary offer is the disputant's demanded outcome, and the secondary offer is the disputant's estimate or “expectation” of the arbitrator's desired outcome (i.e., the average arbitrator settlement preference). Arbitrators evaluate the pair of final offers of each disputant and assign a value to the pair of final offers. Specifics are given in the next section, but the procedure's rules are such that, when arbitrators weigh a disputant's estimate of the arbitrator's settlement preference more than the disputant's demanded outcome in evaluating the pair of final offers, secondary final offers will theoretically converge and arbitration is unnecessary—settlement is simply the converged secondary offers.

Since double-offer arbitration promises to reduce (i.e., eliminate) disputes, an empirical examination of bargaining outcomes under this procedure is prudent. This theoretical procedure is not used in practice, however, and so initial data is generated in a controlled laboratory setting. The results indicate that disputes are not eliminated under double-offer arbitration, but rather they are similar to average dispute rates under conventional arbitration. In fact, when dispute 
occurs, the innovative procedure may cause concern because it is shown, both theoretically and empirically, to cause final bargaining positions to diverge widely. The concern is that certain arbitration procedures utilize one of the disputant's final offers as the arbitrated settlement, and so extreme final offers imply extreme outcomes. However, for the subset of rounds where disputants have common expectations about likely arbitration outcomes, the rule's procedures guarantee no dispute. This implies no need to ultimately invoke the procedure when bargainers are not “optimistic” about arbitrator settlement preferences. ${ }^{2}$ Finally, a probit estimation of dispute rates adding controls for arbitration history shows that both conventional and final-offer arbitration are addictive. That is, previous use of either procedure increases the probability that disputants will use the procedure in the future. Double-offer arbitration, however, is not addictive. The absence of a "narcotic" effect, though not part of the formal theory, would benefit all disputants who might engage in repeated bargaining with a counterpart (e.g, grievance arbitration in unionized firms).

\section{The Double-Offer Arbitration Procedure}

The reader is directed to Zeng et al. (1996) for a thorough theoretical examination of the double-offer arbitration procedures. Here, I summarize the important features of the procedure, and the conditions under which the convergence results holds.

Consider a buyer, b, and a seller, s, in dispute over the size of a variable x (e.g., the price in a transaction). The buyer's (seller’s) utility is decreasing (increasing) in the size of x. The rules of double-offer arbitration require the submission of "double” final offers, a primary final offer, $x_{i}$, and a secondary final offer, $y_{i}$, from both the buyer and seller $(i=b, s)$. The arbitrator is assumed to have his own notion of a fair settlement, $z_{\mathrm{a}}$, which is a draw from the density function $f($.$) describing the disputants' uncertainty about arbitrator settlement preferences. Assuming that$ 
neither primary nor secondary final offers converge—if so the settlement would be the midpoint of the converged offers - the arbitrator proceeds to evaluate each disputant's double offers with a linear criterion function $\mathrm{C}_{\mathrm{s}}$ or $\mathrm{C}_{\mathrm{b}}$ for the seller and buyer, respectively. The lower criterion function value determines the arbitration "winner", and the winner receives his primary offer as the binding arbitration settlement. A lottery determines the winner in the event that $\mathrm{C}_{\mathrm{s}}()=.\mathrm{C}_{\mathrm{b}}($.$) .$

$$
\begin{aligned}
& \mathrm{C}_{\mathrm{s}}\left(\mathrm{x}_{\mathrm{s}}, \mathrm{y}_{\mathrm{s}} \mid \mathrm{z}_{\mathrm{a}}\right)=\alpha\left|\mathrm{y}_{\mathrm{s}}-\mathrm{x}_{\mathrm{s}}\right|+(1-\alpha)\left(\mathrm{y}_{\mathrm{s}}-\mathrm{z}_{\mathrm{a}}\right) \\
& \mathrm{C}_{\mathrm{b}}\left(\mathrm{x}_{\mathrm{b}}, \mathrm{y}_{\mathrm{b}} \mid \mathrm{z}_{\mathrm{a}}\right)=\alpha\left|\mathrm{y}_{\mathrm{b}}-\mathrm{x}_{\mathrm{b}}\right|+(1-\alpha)\left(\mathrm{z}_{\mathrm{a}}-\mathrm{y}_{\mathrm{b}}\right)
\end{aligned}
$$

The parameter $\alpha \in(0,1)$ is determined by the arbitrator and is known a priori by the disputants. Given the criterion functions (1) and (2), it can be noted that there are two ways in which a disputant can lower (i.e., improve) his criterion function value in making the double offer. First, primary and secondary offers that are close will minimize the first portion of the criterion function for a given $\alpha-$-note the use of absolute values only in the first terms of (1) and (2). Secondly, a secondary offer that is close to or even beyond the disputants' belief of $z_{a}$ will also lower the criterion function value. Since we have described secondary offer $y_{i}$ as disputant $i$ 's estimate of $\mathrm{z}_{\mathrm{a}}$, the second term of the criterion function rewards disputants who are unbiased (even pessimistic) about $\mathrm{z}_{\mathrm{a}}$. Optimistic buyer (seller) beliefs would mean that $y_{\mathrm{b}}\left(y_{\mathrm{s}}\right)$ is biased towards outcomes that are lower (higher), on average, than the true mean of the arbitrator settlement distribution, $z_{\mathrm{a}}$. While the secondary offer is a type of fair settlement estimate, the primary final offer can be described as the disputant's real demand for $\mathrm{x}$ given that the winning disputant is granted his primary final offer as the binding settlement. As summarized by Zeng et al. (1996) “...[i]n FOA [final-offer arbitration], the single offer of a disputant summarizes both his/her real demand and his/her estimate of a fair settlement. However, estimate and demand are separate in DOA [double-offer arbitration].” (p. 150-1). 
The key convergence result requires that the arbitrator places greater emphasis on secondary offers, or expectations, such that $\alpha<.5$. In this case, Zeng et al. show that the unique global Nash equilibrium double offers are given by

$$
\left[\left(\mathrm{x}_{\mathrm{S}}^{*}, \mathrm{y}_{\mathrm{s}}{ }^{*}\right),\left(\mathrm{x}_{\mathrm{b}}{ }^{*}, \mathrm{y}_{\mathrm{b}}{ }^{*}\right)\right]=\left[\left(m+\frac{1-\alpha}{2 \alpha f(m)}, m\right),\left(m-\frac{1-\alpha}{2 \alpha f(m)}, m\right)\right]
$$

where $m$ is the median of the arbitrator settlement preference distribution, $f($.$) . In other words,$ the secondary offers of both disputants in (3) are $m$. This secondary offer convergence implies automated settlement at the converged upon value, $m$ in this case, under the procedure's rules.

For this range of parameters $\alpha<.5$, the incentive for accurate expectations dominates the bargainer's incentive to compromise between primary and secondary offers—see the criterion equation functions (1) and (2). It is this incentive, which results from the specification of the criterion function, that theoretically induces both bargainers to submit the true median value of $f($.$) as the secondary offer. So, in the end, arbitration is not used when final offers-in this case,$ the secondary offers - converge. It is also worth noting that equilibrium primary offers in (3) diverge from $m$ by the term $\frac{1-\alpha}{2 \alpha f(m)}$, which implies increasingly divergent primary offers as $\alpha$ approaches zero. Though this should not matter since secondary offers theoretically converge for $\alpha<.5$, any small error in expectations accuracy for either bargainer might produce an extreme arbitration outcome given the predicted divergence in primary offers (one of which will be the arbitrated settlement under the procedure's rules). For the other range of parameters $\alpha>.5$, Zeng et al. show that the unique local Nash equilibrium is one in which both primary and secondary offers are the same as in final-offer arbitration (i.e., no convergence).

The potential value in double-offer arbitration lies in its ability to induce convergence of secondary offers to the median of the arbitrator settlement distribution when $z_{a}$ estimates (i.e., 
expectations) are emphasized. An underlying assumption is that disputants have a common belief of $z_{a}$. If beliefs are optimistic, disputants would then submit divergent secondary offers. However, recall that double-offer arbitration rewards non-optimistic expectations, because they lead to a smaller second term of the criterion function. Therefore, an additional benefit of the procedure is that it may also help reduce disputant bias by making optimism costly. This is significant given that biased expectations are often cited as a primary cause of bargaining impasse (Farber and Bazerman, 1989; Babcock and Loewenstein, 1997; Babcock et al., 1997). This innovative procedure internalizes expectations into its rules, and it is this feature that makes it potentially more attractive than some other innovative procedures that yield similar convergence results (e.g., the "combined” arbitration procedure of Brams and Merrill, 1986). Ultimately, of course, it is an empirical question whether or not disputes are reduced with double-offer arbitration, and so we next turn to an experimental examination of disputant behavior to answer this question.

\section{The Experiments}

Subjects are randomly assigned a counterpart, and it is common knowledge that one bargains with the same counterpart for a twenty-round experiment. ${ }^{3}$ The experiment is run through computer terminals, and on-screen instructions are summarized by the experimenter. Win-loss bargaining over a variable, $\mathrm{x}$, is induced by means of payoff tables. Subject A (B) receives more money for lower (higher) values of $\mathrm{x}$. While each subject is aware of his own payoff table, and aware that bargaining is win-loss, payoff levels for different x-outcomes are private information. Subjects exchange offers via the computer terminals and subjects have 2 minutes to voluntarily agree (or not) upon a value of $\mathrm{x}$. The experimental bargaining environment is quite unstructured in the sense that there are no explicit rules that offers must 
alternate, improve, or even that any offers be made during the bargaining round. In the event that the round expires with no agreement, subjects are prompted to submit official final offers (double offers in the case of double-offer arbitration) and subjects then proceed to formal impasse resolution in the event that final offers do not either converge or criss-cross (i.e., Subject A final offer $>$ Subject B final offer) to agreement.

There are four distinct impasse resolution procedures used in the twenty-round experiment. Subjects bargain for five consecutive rounds under instructions outlining the use of each different procedure. The impasse resolution procedures used include the three arbitration procedures, conventional, final-offer, and double-offer arbitration (with $\alpha=.25$ ), and a benchmark "no arbitration" procedure that gives subjects a payoff of zero in the event of impasse. Different subject groups proceed through the procedures in different orders. Subjects are aware that the total number of rounds is twenty, but they are not ex ante aware that the rules of dispute resolution will change every five rounds. In the event of impasse under any of the arbitration procedures, the procedure utilizes the subjects' final offer(s), a random draw from the computerized arbitration distribution, $f(x)$, and the rules of the procedure to determine a binding settlement of $\mathrm{x}$ for the round. At the beginning of each conventional and final-offer arbitration round, each subject is asked to give his expectations of the likely draw from the computer arbitrator (i.e., the "computer decision-maker”) distribution. Subjects are informed that their expectation from one of the rounds will be randomly chosen at the end of the experiment, and an additional \$2 payoff will be given for an accurate expectation—an expectation within ten x-units above or below the true average of the computer decision-maker distribution, $f(x)$. Information on $f(\mathrm{x})$ is given to each subject by means of a table of one-hundred past draws from the $f(\mathrm{x})$ 
distribution used in the experiment (a Normal $(\mu=500, \sigma=60)$ distribution), following Ashenfelter et al. (1992). ${ }^{4}$

The use of arbitration has no monetary cost in these experiments. Other researchers include explicit monetary costs of arbitration into their design (see Deck and Farmer, 2003; Pecorino and Van Boening, 2001). This feature of the design makes it such that disputes should only exist if subjects differ in their risk preferences or expectations of arbitration outcomes. Asymmetric information on the computerized arbitrator is, in general, a potential additional source of dispute, but the design controls the information on the computerized arbitrator to be identical for all subject-pairs. Though the addition of a monetary cost to arbitration is certainly more parallel to naturally occurring environments, this design focuses more exclusively on the role of "uncertainty" costs of arbitration in promoting voluntary settlements (as highlighted in Stevens, 1966).

\section{Results}

This section reports results of data generated from 52 subject pairs (i.e., $\mathrm{N}=1040$ rounds of data). The experiment lasted just under 1.5 hours, and average earnings for each individual subject were approximately \$20. The data are presented in summary form in Figures 1 and 2. Figure 1 shows dispute rates for each round of the experiment, averaged across all bargaining pairs. One can see the downward trend in dispute rates that may indicate that subject learn over the course of the 20-round experiment. The order in which subjects see different dispute resolution treatments is varied by experiment group, and so there may be trends across the five rounds of each treatment that are masked by the aggregation in Figure 1. ${ }^{5}$ Figure 2 shows dispute rates by treatment, averaged across all bargaining pairs for each round within the treatment. Not only are the higher dispute rates for the arbitration treatments, relative to the no- 
arbitration (NA) treatment, apparent in Figure 2, but one can also identify a downward trend in dispute rates for the double-offer arbitration treatment. This trend does not appear for the commonly used arbitration procedures, and this will be discussed further during the presentation of the Table 1 results (i.e., the models in columns (2) and (3) of Table 1).

The main statistical analysis of the data is shown in Table 1 . A random effects probit model is used to estimate the probability of dispute under the assumption that subject pairs in the experiment represent a random sample of a larger population of bargaining pairs. The random effects estimation controls for interpair heterogeneity in the data and also the potential nonindependence of error terms across rounds for a given subject pair. ${ }^{6}$ Three models are estimated: column (1) of Table 1 shows results from a basic treatment effects modeling of dispute rates, while columns (2) and (3), also include controls for bargaining experience of the subject pairs. In column (2) of Table 1 we include variables controlling for cumulative experience in the bargaining environment (Round) and experience utilizing each distinct arbitration procedure (the History variables). The model in column (3) in Table 4 also includes variables controlling for the number of no-dispute or settlement rounds for each treatment the subject-pair has accumulated up to the present round. The difference between these final two models is that the column (3) can distinguish any behavioral difference between subject pairs who have utilized a given arbitration procedure the exact same number of times, but one of the pairs has voluntarily settled more (or less times) within that treatment. That is, this model explicitly distinguished between good (voluntary settlement) and bad (dispute) bargaining experience within each treatment.

The marginal effects shown in column (1) of Table 1 indicate that, relative to the noarbitration treatment, all arbitration procedures significantly increase the probability of dispute. 
This is consistent with Ashenfelter et al. (1992), among others, and it is not surprising given that the arbitration procedures in this experiment lower the cost of dispute relative to the zero-payoff treatment. Also consistent with existing laboratory research, it is estimated that dispute rates are marginally higher in final-offer than in conventional arbitration (Ashenfelter, et al., 1992;

Dickinson, 2004; Deck and Farmer, 2003). It is also apparent from Table 1 that dispute rates are not significantly improved overall by the use of double-offer arbitration. The marginal increase in the probability of dispute, relative to no-arbitration, is significantly lower in double-offer and conventional arbitration than in final-offer arbitration $(\mathrm{p}=.00$ and $\mathrm{p}=.02$, respectively, for the Wald test of the restriction). However, there is no significant difference in the estimated marginal effects of double-offer and conventional arbitration ( $\mathrm{p}=.62)$. Expectations are a critical factor in comparing the success of any arbitration procedure since real world negotiators may have biased estimates of impasse outcomes (see Babcock et al., 1993; Babcock et al., 1996). So, prior to discussing the remaining Table 1 results in columns (2) and (3), I first discuss some additional results that stem from exploring the role of optimism in the data generation process.

A more detailed look at dispute rates is accomplished by dividing the data into optimistic and non-optimistic sub samples-non-optimistic includes pessimistic pairs as well as unbiased pairs. The data coding on expectations is at the pair level. Pairwise optimism indicates that the subject B (seller) expectations minus subject A (buyer) expectations are greater than zero. For example, if subject A, subject B beliefs of [350,480], [495,510], and [550,675] for likely outcomes from arbitration would all be coded as "pairwise optimism". Given the structure of the no-arbitration and double-offer arbitration treatments, expectations are not elicited at the beginning of the bargaining rounds. For expectations of $f(x)$ in double-offer arbitration, secondary final offers are somewhat comparable to expectations elicited at the beginning of the 
rounds in conventional and final-offer procedures. When eliciting expectations in conventional and final-offer arbitration, recall that subjects have a monetary incentive to be accurate. Specifically, subjects are informed that one round is drawn at random from the conventional and final-offer arbitration rounds at the end of the experiment, and \$2 is added to their compensation if the expectation recorded for that round is accurate. ${ }^{7}$ The main differences are that secondary final offers are never obtained when subjects reach agreement during the course of the round and, when they are obtained, it is at the end rather than the beginning of the round. In the noarbitration treatment, expectations are not elicited at all since the zero payoff of impasse is known with certainty. These details of the data set and data comparability across treatments render the statistical analysis less than straightforward, but the general picture of how optimism affects disputes in the different arbitration procedures is still quite clear.

For those bargaining pairs that have some degree of optimistic expectations in a given round a dummy variable is coded equal to one for pairwise optimism in that round. This is true of about $81 \%$ of the sample of observations in the arbitration treatments. For double-offer arbitration, we only code as optimistic those pairs who reach the end of the round so that we have data on optimistic secondary offers. Table 2 shows results in column (1) from a random effects probit model that indicates that the probability of dispute is statistically significantly increased by $48 \%$ when the bargaining pair is optimistic about $f(x)$, consistent with comparable laboratory evidence in Dickinson (2004). This does not, however, estimate a differential effect across arbitration treatments. The model in column (2) of Table 2 instead includes two variables interacting pairwise optimism with conventional and final-offer arbitration. ${ }^{8}$ These results now indicate that optimism increases disputes by slightly more in final-offer than in conventional arbitration, although the effects are statistically insignificant. Given this, it is clear that most of 
the decrease in probability of dispute for nonoptimistic pairs comes from the double-offer arbitration treatment. The results in Table 2 reflect the fact that the double-offer arbitration rules dictate a settlement for non-optimistic pairs. This makes the optimism results from column (1) seem a bit less informative, but the general optimism result is consistent with existing research.

One drawback from the double-offer arbitration procedure is that when secondary offers do not converge, the arbitrated settlement is one of the disputant's primary offers. Theory predicts these to diverge more than final offers in final-offer arbitration when $\alpha<.5$ (see equation (3)), and so outcomes will be more extreme and potentially less acceptable if the procedure does not work as expected. Looking at the subset of disputed rounds in both these procedures, we find that final offers of buyer and seller diverge by 129.9 units in final-offer and by 181.3 units in double-offer arbitration. As predicted, arbitrated settlements are more extreme in double-offer arbitration when secondary offers do not converge, regardless of the reason for non-convergence.

As for dispute rates, the most commonly used metric for success of dispute resolution procedures, the conclusion is somewhat mixed for the innovative arbitration procedure. Dispute rates are not that different between conventional and double-offer arbitration, which is contrary to the theoretical convergence prediction of double-offer arbitration. On the other hand, the theoretical prediction assumes unbiased beliefs, and the majority of the subject pairs are optimistic. When measuring expectations in the experiment, if we assume that secondary offers are comparable to expectations elicited in final-offer and conventional arbitration, then doubleoffer arbitration reduces disputes to zero for unbiased and pessimistic bargaining pairs. This is not surprising since the procedure forces settlement when secondary offers converge, but the resulting settlement is still likely to be more acceptable overall than the alternative arbitrated settlement that would give one disputant his primary offer. In comparison, for unbiased and 
pessimistic pairs in the other arbitration treatments, disputes still occur about 15\% of the time. The fact that double-arbitration procedure completely avoids arbitrated outcomes for nonoptimistic disputants may seem uninformative given the procedure's rules. Nevertheless, these rules reward non-optimistic disputants and allow them to avoid the arbitration procedure in the end. The risk of the procedure is that non-convergence of secondary offers (e.g., a slight error or bias in expectations) implies even more extreme arbitrated settlements than in final-offer arbitration.

\section{Double-Offer Arbitration: non-habit-forming?}

Dispute rates are the most readily measurable and widely used statistic to assess the effectiveness of dispute resolution procedures in general. However, much has also been said about the so-called "narcotic" effect, which states that arbitration may become addictive and replace good-faith efforts by disputants to negotiate voluntary settlements. In long-term relationships and potential repeated bargaining situations, such as grievance arbitration in labormanagement relations, the potential for disputants to become addicted to arbitrated settlements can be a significant concern. Bolton and Katok (1998) study the narcotic effect in repeated laboratory bargaining and find that learning is slowed by arbitration. Their result illuminates some of the mixed evidence that had been found from field studies that examine the narcotic effect of arbitration but ignore the impact of learning over time. A more heavy reliance on arbitration over time would merely worsen the concerns of having lower quality or less efficient outcomes via the arbitrator.

The repeated negotiations environment reported in this article lends itself to examining the possibility of a narcotic effect for each of the distinct arbitration procedures. I take a classic interpretation of the narcotic effect—-the probability of dispute in the current round being 
positively related to the extent to which the arbitration procedure has already been used (see Butler and Ehrenberg, 1981)—along with learning effect insights from Bolton and Katok (1998) to examine this issue in the current data. Specifically, general learning is examined with a variable, Round=1-20, which provides a measure of experience in lab negotiations for each subject pair. Along with this variable, I include four separate arbitration history variables, $N A$ History, CA History, FOA History, and DOA History, that measure the cumulative prior use of each separate dispute resolution procedure within its treatment rounds. As such the History variables can each take on values 0-4 within each treatment given that there are 5 rounds per treatment. Similar to the procedure in Bolton and Katok (1998), there are controls for both learning from bargaining outcomes (the History variables) as well as general experience learning (Round), though I separate "outcomes learning” for each of the four dispute resolution treatments. ${ }^{9}$

Even with these controls for learning, it may still be the case that two bargaining pairs with a given amount of bad history (i.e., dispute) within any particular arbitration treatment may behave differently if their "good" history differs within the treatment (i.e., voluntary settlement rounds). The round variable does not distinguish between such good and bad history, and it is not treatment specific. As such, four additional variables are introduced—-the Settlement History variables- to capture any behavioral differences of this type. ${ }^{10}$ These variables will also take on values from $0-4$.

Column (2) of Table 1 shows random effects probit estimates of the treatment effects along with the controls for arbitration use history and general learning. The estimated marginal effect on general learning, as captured by Round, indicates that subjects are significantly less likely to dispute the more experience they gain in their lab negotiations (6\% less likely to dispute 
for each 10 rounds of experience). This indicates that the bargaining subjects learn from experience, as also noted in Bolton and Katok (1998). ${ }^{11}$ In the present data, there is no real evidence that a subject pair's probability of dispute is negatively related to previous disputes within the no-arbitration treatment. The point-estimate of the marginal effect on NA is negative, but it is statistically insignificant. On the other hand, the commonly used forms of arbitration, conventional and final-offer arbitration, show evidence of a narcotic effect. Each additional round in which a subject pair has previously utilized one of these procedures to settle a dispute increases the probability of dispute in the current round of that specific treatment by $7 \%-9 \%$, independent of any general learning across rounds. This is evidence in support of a narcotic effect hypothesis for arbitration, and the estimated marginal effects also indicate that a round of dispute in conventional or final-offer arbitration offsets more than ten rounds of general lab bargaining experience. In sum, bargainers show evidence of habit formation in the commonly used arbitration procedures, and the negative effects of this vastly outweigh the positive learning trend in the data.

The narcotic effect is, however, curiously absent for double-offer arbitration. The estimated marginal effect of DOA History on the probability of dispute is statistically no different than zero. This is a significant finding that distinguishes this innovative procedure from the commonly used arbitration procedures. Of course, the narcotic effect is an important empirical phenomenon that theoretical examinations of arbitration procedures typically ignore. Some speculation would be that double-offer arbitration is non-addictive because of the way in which disputants are forced to review their beliefs about arbitrator preferences and impasse outcomes. Even though the average subject remains optimistic with respect to arbitrator preferences, the exercise of formulating double offers involves more reflection on both demand 
and expectations than one finds in commonly used arbitration. It is this exercise that may help sever the link between current round behavior and past history of double-offer arbitration use. As hypothesized by Bolton and Katok (1998), “...[i]t is not apparent to us that outside party intervention need slow bargaining learner.” (p. 29). This seems to be the case for double-offer arbitration in repeated bargaining situations.

Finally, the model in column (3) of Table 1 includes controls for both bad and good treatment-specific learning. Results are largely similar to the column (2), with the exception of the coefficient on DOA Settlement History. The marginal effect on this coefficient indicates that there is a decrease in the probability of dispute under double-offer arbitration of $10 \%$ for each additional round of voluntary settlement history under this procedure. So, not only does there appear to be no narcotic effect of double-offer arbitration, but the results indicate that the more subjects utilize the procedure, the less they are likely to use it in the future.

\section{Conclusion}

This article provides a first source of data on an innovative arbitration procedure called double-offer arbitration. The motivation for exploring bargainer behavior under this procedure is that it possesses a theoretical property of convergence of secondary offers, which is sufficient to generate agreement under the procedure and avoid the need to invoke arbitration. The prospect of increasing voluntarily negotiated settlements relative to the commonly used conventional and final-offer arbitration procedures is of significant interest. Not only do lower dispute rates imply cost savings from a lesser need to utilize the arbitration institution, but arbitrated settlements are also considered of lower quality and potentially less efficient than negotiated settlements (Crawford, 1979; Farber, 1980). In addition to examining dispute rates, final bargaining 
positions and evidence of potential addiction to arbitration (i.e., narcotic effects) are also reported. These represent different outcome dimensions for comparing arbitration procedures. Repeated bargaining experiments allow subject-pairs to engage in win-loss bargaining under the distinct arbitration procedures of conventional, final-offer, and double-offer arbitration. A pure treatment effects empirical model shows that the probability of dispute in double-offer arbitration is not significantly different from that in conventional arbitration, though both are lower than the dispute probability in final-offer arbitration. The lack of support for the theoretical prediction of reduced disputes is likely due to the average subject optimism in the data. When controls are added for subject beliefs, double-offer arbitration works exactly as predicted, not surprisingly. This is by design because secondary offers in this procedure are essentially the subject estimates of the likely arbitrator preference for the disputed variable $\mathrm{x}$. When subjects are unbiased, these estimates converge and when the arbitrator weighs the estimates more than subject demands in evaluating each individual's pair of final offers, theoretical secondary offers are precisely these unbiased estimates. Convergence of secondary offers generates an automated settlement as per the rules of the procedure, and so double-offer arbitration guarantees settlement for the subset of unbiased subjects. This may seem to creatively force subjects to agreement, but subjects have complete liberty in submitting double offers and so the result is incentive-based and it rewards good (i.e., accurate) expectations.

Even if one believes that secondary offers are not perfectly correlated with beliefs in double-offer arbitration, less optimistic bargaining pairs have been shown to dispute less frequently across different arbitration procedures (see Dickinson, 2003), though the present data on this procedure would be more difficult to interpret without a reliable measure of expectations. A drawback of the procedure is that arbitrated settlements are more extreme when secondary 
offers do not converge. So, optimism not only increases the likelihood of dispute, but it also implies that arbitrated settlements are more extreme under the innovative procedure than under final-offer arbitration. This may be a concern since extreme settlements is a commonly noted criticism of final-offer arbitration (see Farber, 1980).

An interesting finding in support of double-offer arbitration is that it does not generate the narcotic effect that is found in the commonly used arbitration procedures. Independent of the general learning trend that lowers dispute probability over time, past arbitration experience in conventional or final-offer arbitration significantly increases the probability of dispute in the current bargaining round. This is not so with double-offer arbitration and, in fact, there is estimated to be an opposite effect whereby a history of voluntary settlement under double-offer arbitration decreases the likelihood that the procedure will be utilized in future rounds. Though the mechanism by which habit formation occurs is not well understood in the context of arbitration, I speculate that this procedure is not addictive because of the way in which bargainers are forced to reflect more in making the more complicated double offers than in making the singular final offers elicited in the commonly used procedures. Perhaps this makes the procedure seem less like a lottery to the subjects, which makes them less likely to base current decisions on past outcomes. Whatever the mechanism, the effect is robust to econometric estimation techniques and may even imply that any arbitration procedure can be improved by eliciting subject expectations and promoting reflection on the likely arbitrated outcomes. 


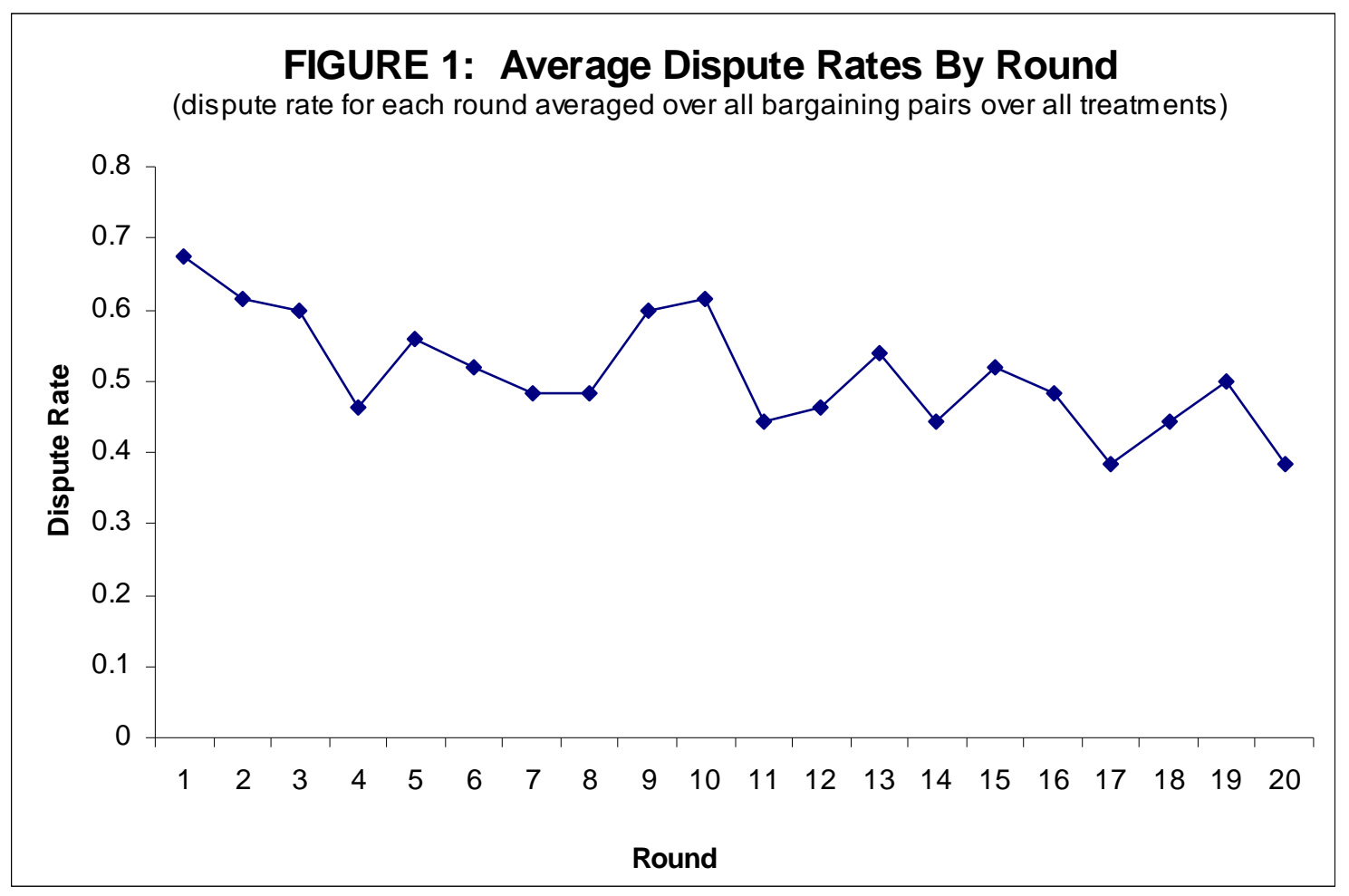




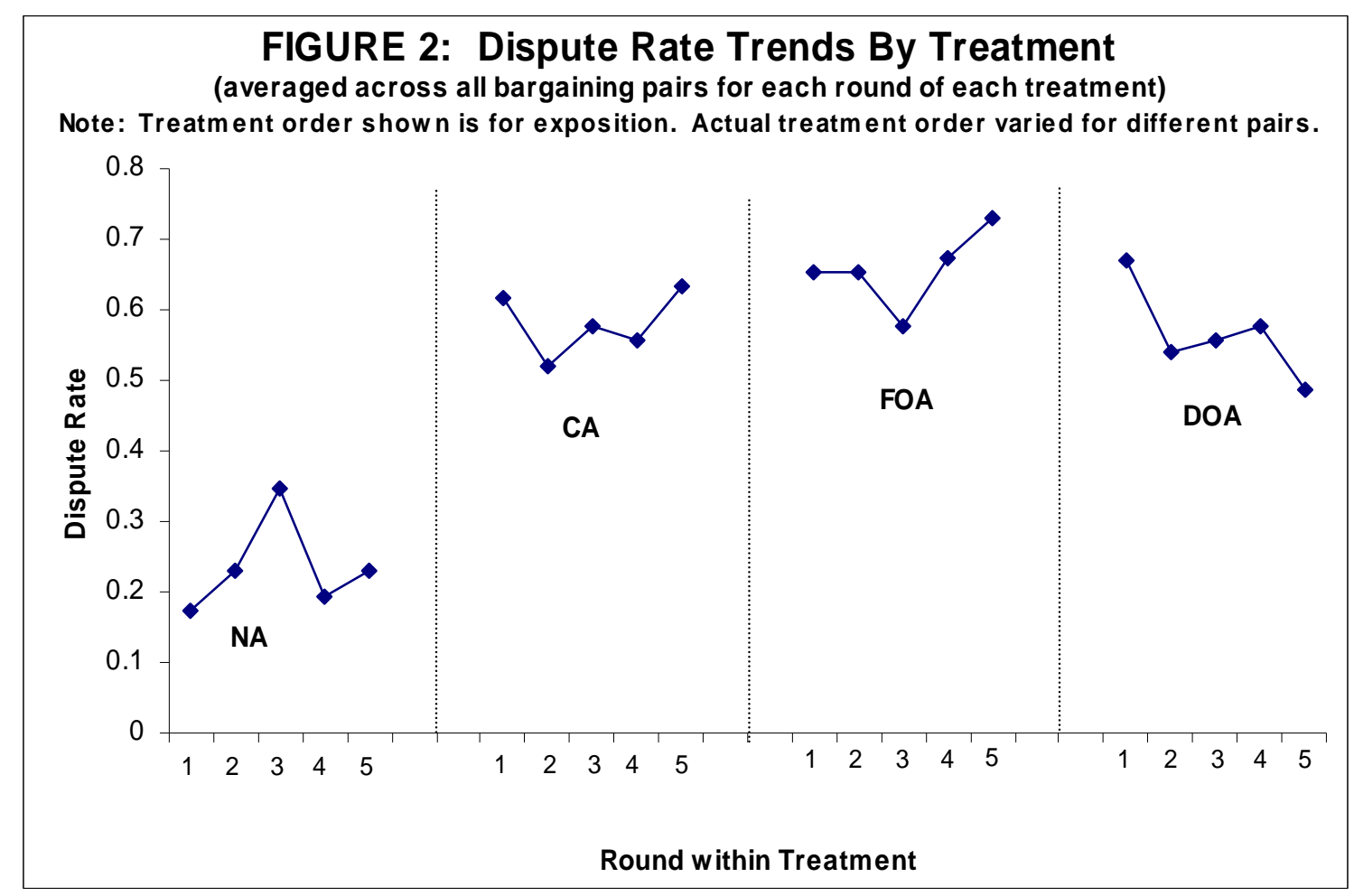


TABLE 1

Dispute rate treatment effects

Random effects probit modeling of dispute=0,1 (N=1040)

\begin{tabular}{|c|c|c|c|}
\hline Variable & $\begin{array}{c}\text { (1) } \\
\text { Marginal effect } \\
\text { p-value }\end{array}$ & $\begin{array}{c}\text { (2) } \\
\text { Marginal effect } \\
\text { p-value }\end{array}$ & $\begin{array}{c}\text { (3) } \\
\text { Marginal effect } \\
\text { p-value }\end{array}$ \\
\hline Constant & $-.28(.00) * * *$ & $-.20(.02)^{* *}$ & $-.26(.01)^{* * *}$ \\
\hline CA & $.36(.00) * * *$ & $.27(.00)^{* * *}$ & $.35(.00) * * *$ \\
\hline FOA & $.44(.00) * * *$ & $.32(.00) * * *$ & $.42(.00) * * *$ \\
\hline DOA & $.34(.00) * * *$ & $.31(.00)^{* * *}$ & $.45(.00) * * *$ \\
\hline Round & -- & $-.006(.01) * * *$ & $-.005(.10)^{*}$ \\
\hline NA History & $\begin{array}{ll}-- \\
--1\end{array}$ & $-.02(.67)$ & $-.02(.76)$ \\
\hline CA History & --- & $.07(.03)^{* *}$ & $.07(.04)^{* *}$ \\
\hline FOA History & --- & $.09(.01)^{* * *}$ & $.09(.02)^{* *}$ \\
\hline DOA History & --- & $.006(.82)$ & $-.002(.93)$ \\
\hline NA \# settlements & --- & --- & $.03(.42)$ \\
\hline CA \# settlements & --- & --- & $-.04(.30)$ \\
\hline FOA \# settlements & --- & --- & $-.06(.24)$ \\
\hline DOA \# settlements & --- & --- & $-.10(.02) * *$ \\
\hline \% correctly predicted & $64 \%$ & $66 \%$ & $69 \%$ \\
\hline Log likelihood function & -582.7 & -571.46 & -563.84 \\
\hline
\end{tabular}

$*^{* *}, * * *$ indicates significance at the $.10, .05$, and .01 level, respectively. 
TABLE 2

\begin{tabular}{|c|c|c|}
\hline \multicolumn{2}{|c|}{$\begin{array}{c}\text { Dispute rate effects of optimism } \\
\text { Random effects probit modeling of dispute=0,1 (N=1040) }\end{array}$} \\
\hline Variable & $\begin{array}{c}\text { (1) } \\
\text { Marginal effect } \\
\text { (p-value) }\end{array}$ & $\begin{array}{c}\text { (2) } \\
\text { Marginal effect } \\
\text { (p-value) }\end{array}$ \\
\hline Constant & $-.28(.00)^{* * *}$ & $-.28(.00)^{* * *}$ \\
\hline CA & $-.02(.78)$ & $.28(.00)^{* * *}$ \\
\hline FOA & $.07(.27)$ & $.34(.00)^{* * *}$ \\
\hline DOA & $.08(.22)$ & $.34(.00)^{* * *}$ \\
\hline Optimistic Pair & $.48(.00)^{* * *}$ & --- \\
\hline Optimistic Pair*FOA & --- & $.13(.19)$ \\
\hline Optimistic Pair*CA & --- & $.10(.20)$ \\
\hline \% correctly predicted & $76 \%$ & $65 \%$ \\
\hline Log likelihood function & -571.49 & -580.10 \\
\hline
\end{tabular}




\section{Author Affiliation}

Department of Economics

Appalachian State University

\section{Acknowledgements}

The author thanks NSF for funding this research through grant SES-0133231. Partial funding was also granted by the Agricultural Experiment Station at Utah State University. This paper has benefited from communication with Dao-Zhi Zeng and the comments of two anonymous reviewers. The author is grateful to Kamalakar Thota, Pablo F. Rego Barros, Jianlin Cheng, Jujun Zhang, and Stacie Gomm for programming the computerized bargaining environment. The author also thanks Nitesh Saha for valuable research support.

\section{NOTES}

${ }^{1}$ The Supreme Court Case is Circuit City Stores v. Adams, 99-1379.

${ }^{2}$ In the context of this paper, optimism is defined for the bargaining pair and refers to the situation where the seller (Player B) expects an arbitrated settlement that is larger than what is expected by the buyer (Player A).

${ }^{3}$ The experimental instructions are available upon request. This same basic experimental bargaining environment is also used in Dickinson (2004), which compares conventional, finaloffer, and “combined” arbitration. Combined arbitration is yet another innovative theoretical arbitration procedure that is not used in practice, but that possesses nice theoretical properties. In the present paper, expectations are elicited in conventional and final-offer arbitration, which was not the case in Dickinson (2004). The expectations data allow one to evaluate the extent to which optimism may be affecting bargaining outcomes.

${ }^{4}$ Since subjects bargain over an abstract variable, $x$, they are given a suggested bargaining range in their instructions. This bargaining range is also highlighted on each individual's payoff sheet, but the center of subject A's suggested bargaining range $(x=450)$ is not the same as the center of subject B’s $(x=550)$. This may increase overall disputes but, since the same bargaining ranges 
are used in all 4 treatments, comparisons of outcomes for a given subject pair across treatments can still identify treatment effects.

${ }^{5}$ There were six experimental groups in total, and the order of the treatments for each group were: (CA,NA,DOA,FOA), (DOA,CA,FOA,NA), (FOA,DOA,NA,CA), (NA,FOA,CA,DOA), (CA,FOA,DOA,NA), (DOA,FOA,NA,CA).

${ }^{6}$ Random effects is considered appropriate for this probit model given that the parameter estimating the degree of interdependence of the error term across rounds for a given subject pair is statistically significant $(\mathrm{p}<.10)$. Nevertheless, comparable linear models were estimated and there are no major differences in key results of such estimations compared to the random effects probit estimations. Results are available upon request.

${ }^{7}$ Here, "accurate" is specifically defined for the subjects as an expectation of the average $\mathrm{x}$ from the "computer decision-maker" (i.e., arbitrator) that is within 10 units above or below the actual average of the arbitrator distribution. This gives subjects a 1/3 standard deviation window for accuracy given the arbitration distribution utilized-normal $(\mu=500, \sigma=60)$.

${ }^{8}$ Optimism is not interacted with double-offer arbitration due to the rules of the procedure. These rules, and the fact that we utilize secondary offers as our indicator of expectations in this treatment, imply that optimistic pairs will be forced to utilize arbitration (i.e., this would perfectly predict disputes)

${ }^{9}$ Bolton and Katok (1998) introduce a slightly different modeling of round versus outcome (i.e., disputes or settlements) in analyzing their data - the concern is potential multicollinearity of round and outcomes variables. I do not follow their exact same procedure primarily because multicollinearity of Round and the History variables is less a concern in the present data, where each dispute resolution treatment makes up only one-fourth of the total number of rounds for 
each bargaining pair. Also, none of the coefficient estimates from the nonlinear probit models presented in Table 1 are sensitive to the use of the random effects probit estimator versus the appropriate linear modeling (i.e., fixed or random effects) of the data. Coefficient estimates from the linear models are virtually identical in magnitude and statistical significance to those from the probit estimates. In sum, the key narcotic effect results are not a function of the estimation technique used. These results are available from the author on request. ${ }^{10}$ The author thanks an anonymous reviewer for suggesting these control variables.

${ }^{11}$ They report that subjects learn from the mistake of dispute. However, it is not clear that disputes are best characterized as mistakes since they may be inherently strategic in repeated negotiations. 


\section{References}

Ashenfelter, Orley., Currie, Janet., Farber, Henry S., and Matthew Spiegel. (1992). “An experimental comparison of dispute rates in alternative arbitration systems.” Econometrica. 60, 1407-33.

Babcock, Linda, Henry Farber, Cynthia Fobian, and Eldar Shafir. (1993). "Forming beliefs about adjudicated outcomes: Perceptions of risk and reservation values.” International Review of Law and Economics. 15, 289-303.

Babcock, Linda., and George Loewenstein. (1997). "Explaining bargaining impasse: The role of self-serving biases.” Journal of Economic Perspectives. 11, 109-26.

Babcock, Linda, George Loewenstein, and Samuel Issacharof. (1997). “Creating convergence: debiasing biased litigants.” Law and Social Inquiry. 22, 401-13.

Babcock, Linda, Xianghong Wang, and George Loewenstein. (1996). "Choosing the wrong pond: Social comparisons that reflect a self-serving bias.” Quarterly Journal of Economics. 111, 1-19.

Bolton, Gary E., and Elena Katok. (1998). "Reinterpreting arbitration’s narcotic effect: An experimental study of learning in repeated bargaining." Games and Economic Behavior. 25, 1-33.

Brams, S., and S. Merrill, III. (1986). "Binding versus final-offer arbitration: a combination is best.” Management Science. 32, 1346-1355.

Brams, Steven J., and Samuel Merrill, III. (1983). “Equilibrium strategies for final-offer arbitration: There is no median convergence.” Management Science. 29, 927-41.

Butler, R. J., and Ehrenberg, Ron. G. (1981). "Estimating the narcotic effect of public sector impasse procedures.” Industrial and Labor Relations Review. 35, 3-20.

Crawford, Vincent P. (1979). “On compulsory arbitration schemes.” Journal of Political Economy. 87, 131-59.

Deck, Cary., and Amy Farmer "Bargaining over an uncertain value: Arbitration mechanisms compared.” Working paper. University of Arkansas.

Dickinson, David L. (2004) “A Comparison of conventional, final-offer, and 'combined' arbitration for dispute Resolution” Industrial and Labor Relations Review, 57(2): 288-301.

Dickinson, David L. “Expectations and comparative arbitration institutions.” Utah State University ERI working paper \#03-02. 
Farber, Henry S. (1980). “An analysis of final-offer arbitration.” The Journal of Conflict Resolution. 24, 683-705.

Farber, Henry S., and Harry C. Katz. (1979). "Interest arbitration, outcomes, and the incentive to bargain.” Industrial and Labor Relations Review. 33, 55-63.

Farber, Henry S., and Max H. Bazerman. (1989). "Divergent expectations as a cause of disagreement in bargaining: Evidence from a comparison of arbitration schemes." Quarterly Journal of Economics. 104, 99-120.

Pecorino, Paul, and Mark Van Boening. (2001). "Bargaining and Information: An Empirical Analysis of a Multistage Arbitration Game." Journal of Labor Economics. 19, 922-48.

Stevens, Carl M. (1966). “Is compulsory arbitration compatible with bargaining?” Industrial Relations. 19, 38-52.

Zeng, D., Nakamura, S., and T. Ibaraki (1996). “Double-offer arbitration.” Mathematical Social Sciences. 31, 147-170. 